\title{
ESTUDIO ANATÓMICO DE DOMACIOS FOLIARES EN TRES ESPECIES DE LA FAMILIA RUTACEAE
}

\author{
por STELLA M. SOLIS ${ }^{\dagger}$
}

\section{Summary}

\begin{abstract}
Exomorphologicai and anatomical studies of leaflets and leaf domatia in three species of Rutaceae were made. Domatia of "revolute margin» type (Metcalfe \& Chalk, 1979) were observed in Fagara pterota and $F$. hyemalis. They are revolute expansions at the base of the leaflet blade. The mites found belong to the genus Tetranychus (Tetranychidae). Domatia named «crypts» (Metcalfe \& Chalk, 1979) are present in Balfourodendron riedelianum. They are found at the junctions of primary and secondary veins, on the underside of leaflets, although there are some in the tertiary vein axils. Morphological and anatomical characters of leaflets and domatia are described and illustrated.
\end{abstract}

\section{Introducción}

El término domacio (del latín domatium: casa pequeña) fue creado por Lundstroem en 1887, quien lo definió como formaciones o transformaciones en las plantas, adaptadas a la ocupación de huéspedes, sean animales o vegetales, los cuales pueden ser de utilidad al hospedante. Clasificó a estas estructuras de acuerdo con su morfología externa en los siguientes tipos: «mechones de pelos», «bolsillos», «sacos», «hoyos o criptas» y «márgenes foliares revolutos» (Metcalfe \& Chalk, 1979).

Muchos autores aceptan la existencia de un mutualismo facultativo en el cual el domacio foliar sirve como refugio y guardería para ácaros beneficiosos, los cuales a su vez reducen eí número de esporas e hifas fúngicas (Pemberton \& Turner, 1989).

Los domacios se desarrollan independientemente de la presencia de ácaros u otros animales (Adamoli de Barros, 1960; Dottori, 1976).

Los domacios foliares están casi exclusivamente limitados a las Dicotiledóneas leñosas, se presentan en especies pertenecientes a más

Becaria de Iniciación de la Secretaria de Ciencia y Técnica, UNNE. IBONE. Casilla de correo 209. 3400 Corrientes, Argentina. de 50 familias de Angiospermas y son de amplia distribución subtropical (Adamoli de Barros, 1961a; Pemberton \& Turner, 1989).

Al realizar investigaciones sobre especies arbóreas de la provincia de Corrientes, la Lic. Sara Tressens ha comprobado hasta el momento la presencia de domacios en 35 especies de Angiospermas; en base a estos antecedentes se seleccionó la familia Rutaceae Juss. y se inició el análisis anatómico y morfológico de estas estructuras en representantes de los géneros Balfourodendron Corr. Méllo ex Oliv. y Fagara L.

En la familia Rutaceae se ha citado la presencia de domacios en bolsillos en Bouchardatia neurococca (F.Muell.) Baill., Euodia xanthoxyloides F.Muell. y Micromelum minutum (T.F.Forst.) Wight \& Arn. (Brouwer \& Clifford, 1990). De estas especies ninguna crece en la Argentina. También se mencionó la presencia de domacios en Balfourodendron riedelianum (Engl.) Engl. (Spichiger \& Stutz de Ortega, 1987), especie del NE argentino, pero su morfología no ha sido estudiada.

\section{Material y Métodos}

Para efectuar las observaciones exomorfológicas y anatómicas se usó material seco, que fue rehidratado hirviénciolo en agua. Se usaron también hojas en diferentes estados de 
desarrollo, conservadas en FAA (formol-ácido acético- alcohol 96 ). Los ejemplares testigos de este material se encuentran depositados en el Herbario CTES.

Se realizaron cortes transversales a mano alzada, que fueron coloreados con safranina diluida y montados en glicerina-gelatina. Se obtuvieron cortes seriados, previa deshidratación en una serie de Alcohol Butílico Terciario y se incluyeron en «Histoplast». Los cortes se realizaron con micrótomo rotativo, de un espe-sor que osciló entre los 8-10 $\mu \mathrm{m}$, se colorearon con Safranina-Fast green (Johansen, 1940) y se montaron en Bálsamo de Canadá.

Para el estudio de la vascularización foliar se diafanizaron las hojas, según la técnica de Dizeo de Strittmatter (1973) y se colorearon con safranina. Se obtuvieron los índices estomáticos según la fórmula:

$$
\frac{S}{E+S} \times 100=
$$

S: Número de estomas por unidad de área.

E: Número de células epidérmicas en las mismas áreas.

Para la descripción de la arquitectura foliar se ha seguido la terminología de Hickey (1974). Para la de los domacios la de Metcalfe \& Chalk (1979).

Las observaciones y fotografías del material se efectuaron con microscopio estereoscópico Wild M5 y microscopio óptico binocular Wild M20. Los dibujos se realizaron con sus respectivas cámaras claras. Para los esquemas se usaron los signos convencionales de Metcalfe \& Chalk (1950), los estomas se representaron con «X».

\section{Material examinado:}

Balfourodendron riedelianum (Engl.) Engl. ARGENTINA. Corrientes, Dep. Ituzaingó, $17 \mathrm{Km} \mathrm{NW}$ de San Carlos, Estancia Rincón Chico, 11-Xi-84, Tressens et al. 2757. Dep. Alvear, Ruta 40 y Bañado Cuay Chico, 11-III-82, Tressens et al. 1994. Dep. Stc. Tomé, Arroyo Chimiray y Ruta 40, 30-XI-80, Tressens 1071.

Fagara hyemalis (A.St.-Hil.) Engl. ARGENTINA. Corrientes, Dep. San Cosme, entre Costa Toledo y Pto. González, 6-I-66, Krapovickas et al. 11896. Dep. Mercedes, Laguna Iberá, Paso Picada, Reserva Natural Provincial del Iberá, 24-II-89, Tressens et al. 3619. Dep. Capital, Riachuelo a $10 \mathrm{Km}$ al sur de Corrientes, 3-IX-72, Schinini et Pueyo 5181. Dep.
Ituzaingó, Rincón del Playadito, $5 \mathrm{Km}$ al $\mathrm{N}$ de San Alonso, 9-VI-94, Tressens et al. 5049.

Fagara pterota L. ARGENTINA. Corrientes, Dep. Capital, Molina Punta, 3-XII-93, Tressens et Solís 4765. Dep. San Cosme, entre Costa Toledo y Pto. González, 6-I-66, Krapovickas et Cristóbal 11894. Dep. San Cosme, Río Paraná y Ayo. San Juan, 25-V75, Schinini et Quarín. 11524.

\section{Resultados}

\section{Fagara L.}

Las especies de este género están ampliamente distribuidas en regiones tropicales y subtropicales. Las nueve especies de Fagara que viven en Argentina tienen hojas compuestas, pinnadas (Escalante, 1961; Tressens, 1981). Dos de estas especies, F. pterota y F. hyemalis presentan, en la base de los folíolos, expansiones revolutas que forman sacos en los que se encontraron ácaros en distintos estados de desarrollo. Estas estructuras foliares son domacios que pueden interpretarse como del tipo "revoluto», descripto para las familias Anacardiaceae (Adamoli de Barros, 1961b), Juglandaceae, Rubiaceae y Dioscoreaceae (Metcalfe \& Chalk, 1979).

\section{Fagara pterota L. (Fig. 1)}

Exomorfología de los folíolos: opuestos, raro alternos; cartáceos; obovados o elípticos; raquis alado (Fig. 1, A); pelos simples cortos (Fig. 1, C) y escasos pelos glandulares de cabezuela pluricelular en ambas caras (Fig. 1, D); puntos translúcidos que corresponden a las células secretoras epidérmicas; margen crenado con glándulas en los senos; ápice retuso; base aguda, atenuada o cuneada con expansiones revolutas que forman los domacios (Fig. 1, A y B); venación pinnada, camptódroma, broquidódroma; vena de primer orden con recorrido derecho, venas de segundo orden alrededor de 4 pares, ángulo de divergencia casi uniforme, $40-50^{\circ}$, curvadas (Fig. 1, F); venas de tercer orden de modelo reticulado al azar; aréolas con vénulas varias veces ramificadas.

Anatomía de los folíolos: en corte transversal por la parte media de la lámina foliar, se observa lo siguiente (Fig. 1, E): 

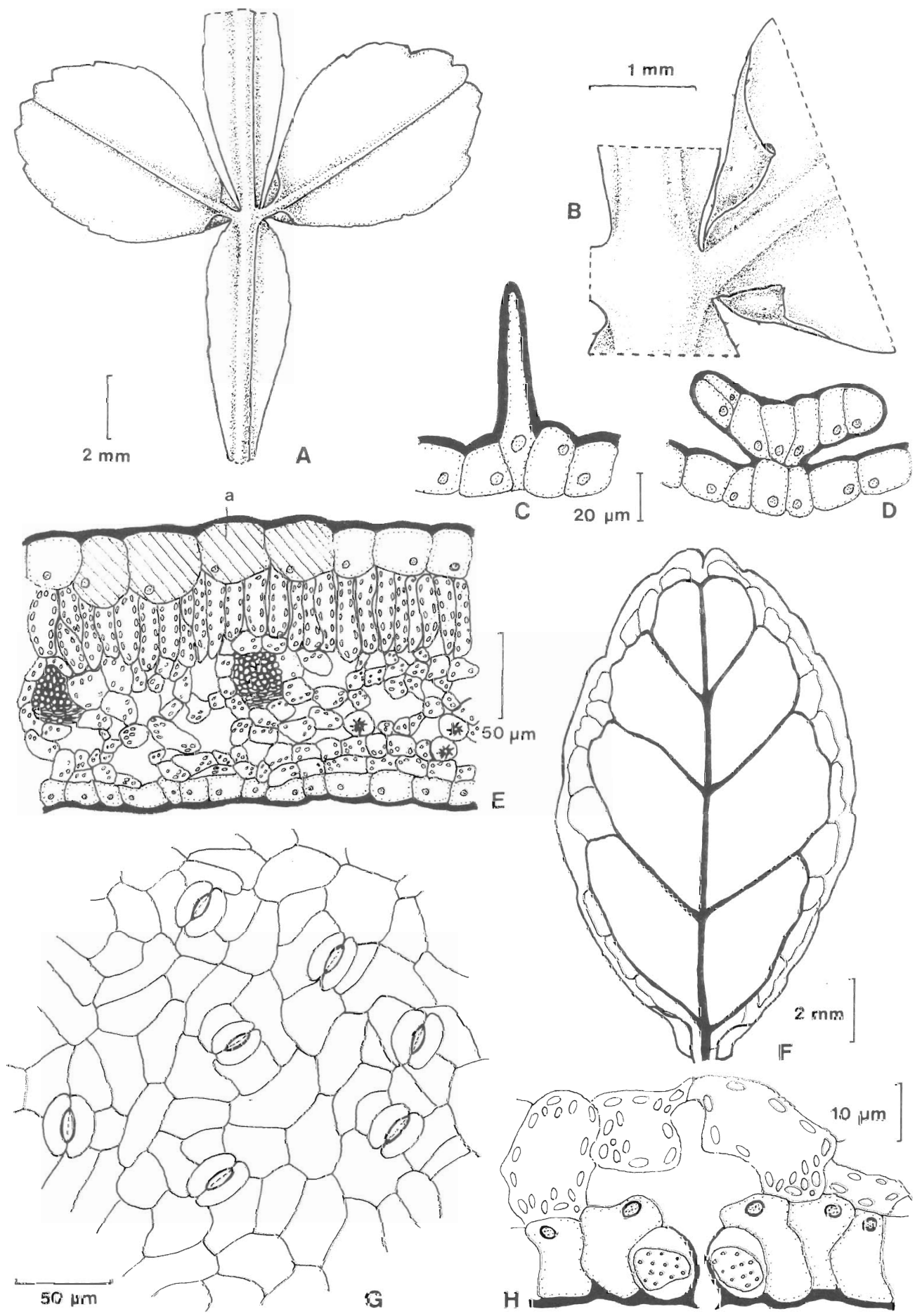

Fig. 1. Fagara pterota (Tressens et Solís 4765). A: cara abaxial de dos folíolos mostrando la ubicación de los domacios; B: detalle de dos domacios revolutos; C y D: pelos de la epidermis foliar; C: pelo simple; D: pelo glandular; E: transcorte del mesofilo; F: venación del folíolo; G: epidermis abaxial dei folíolo; H: estoma de un folíolo en transcorte; a, células secretoras. 


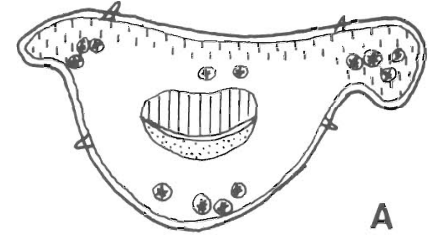

A
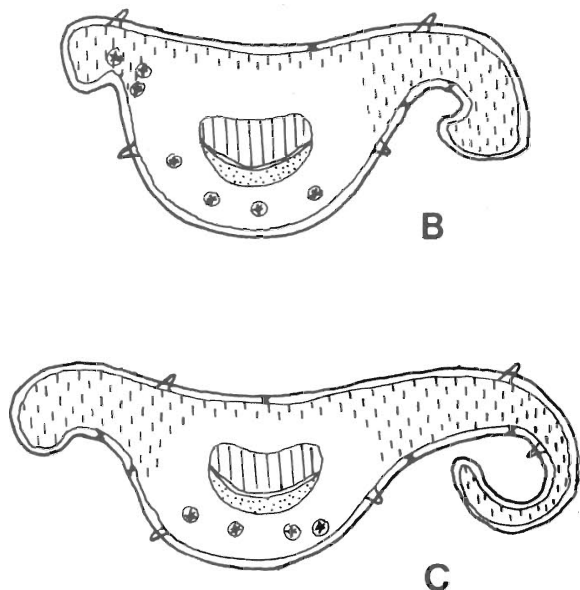

C

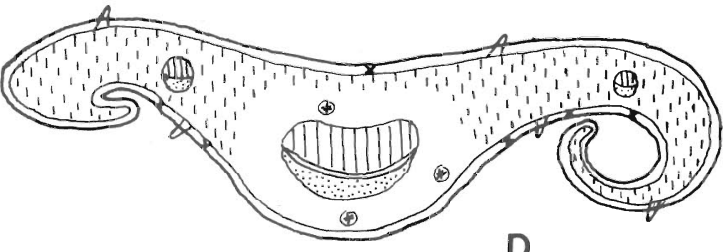

D
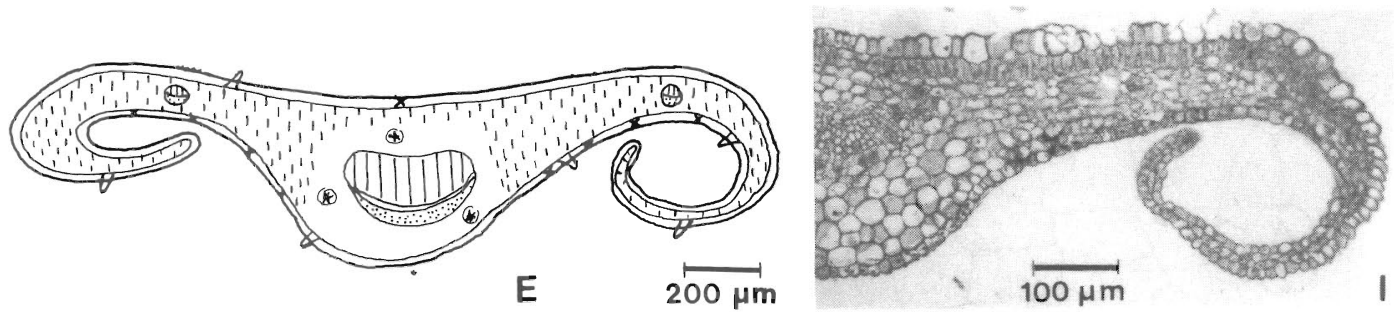

Fig. 2. Fagara pterota (Tressens et Solís 4765). A-E: representación esquemática de secciones transversales del domacio desde la base foliar hacia el ápice; F-I: fotomicrografías de las zonas esquematizadas en A-E.

Epidermis adaxial uniseriada; abundantes células secretoras mucilaginosas de gran tamaño; cutícula estriada. Mesofilo de estructura dorsiventral; cavidades secretoras lisígenas en los márgenes de la lámina y en el parénquima que rodea la vena media; los haces de conducción colaterales; abundantes idioblastos
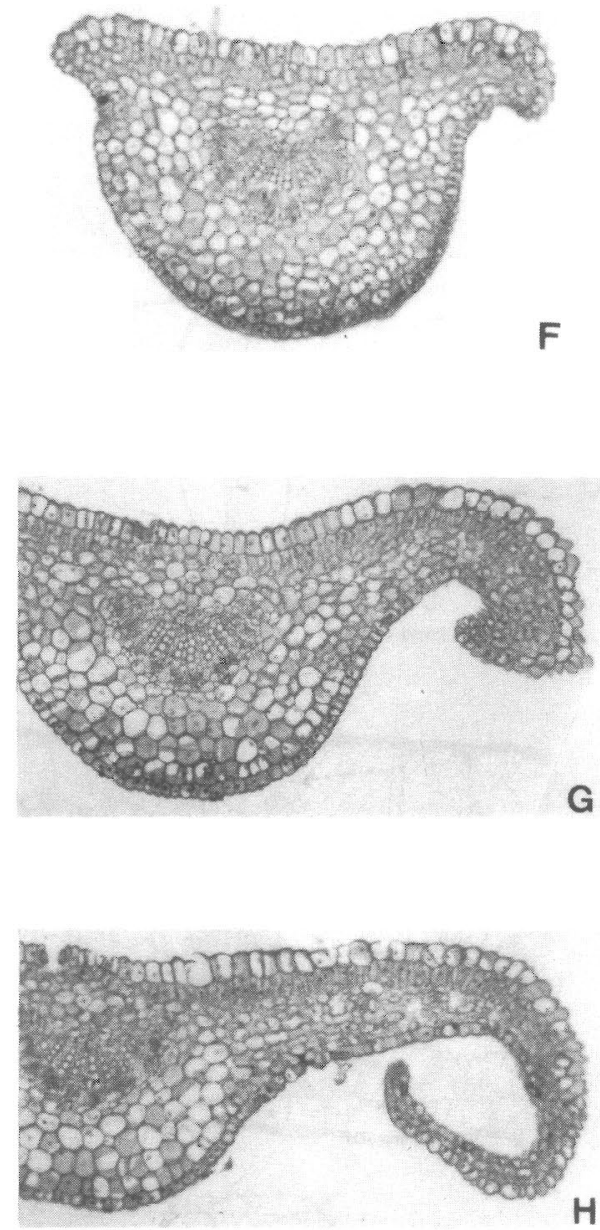

$\mathrm{H}$ 
mente estriada, siendo la estriación aún más notable sobre las células oclusivas; índice estomático de 10 a $12 \%$. Vena media formada por un haz colateral abierto rodeado de células parenquimáticas, con abundantes idioblastos, drusas y cristales prismáticos simples.

Exomorfología del domacio (Fig. 1, A): La lámina foliar a nivel del domacio es membranácea y de un verde más pálido que el resto de la lámina, el margen es generalmente lacinia. do, se observan pelos simples en la cara externa e interna del domacio, los cuales son iguales a los que se presentan en el resto del folíolo. Estos domacios por su ubicación se los considera baso-laminares (Stace, 1965); siempre presentes uno a cada lado de la base de la lámina.

Anatomía del domacio: Se realizaron cortes seriados desde la base foliar hacia el ápice (Fig. 2, A-I). Se describe a continuación lo observado en esa secuencia:

En la base de la lámina foliar las células epidérmicas de la cara adaxial se presentan estrechas, dispuestas en empalizada, con núcleos grandes refringentes fuertemente coloreados. El tejido clorenquimático presenta células isodiamétricas. Este tejido se caracteriza por sus células llenas de cristales, con gran predominio de drusas que se hacen más abundantes a nivel de la base del domacio con relación al resto del folíolo en el cual el número de drusas es menor (Fig. 2, A y F).

Los domacios se proyectan a cada lado del peciólulo, en forma simétrica o asimétrica cuando uno de los lados presenta un retardo en el desarrollo (Fig. 2, B y F).

En la parte media del domacio, la lámina se pliega en forma de lengüeta y luego se dobla hacia abajo y hacia adentro. A este nivel se diferencian las células del parénquima clorofílico en empalizada hacia la cara superior y del lagunoso hacia la cara inferior (Fig. 2, C y G).

La porción de lámina que forma el domacio presenta haces vasculares colaterales cerrados sólo en la región no revoluta (Fig. 2, D y H). Estos haces corresponden a las venas de segundo orden y de órdenes mayores de venación.

En la región de máximo plegamiento, la lámina presenta sólo una hilera de células clorenquimáticas entre ambas epidermis (Fig. 2, E e I).
No se observan estomas en la epidermis que tapiza la cara interna del domacio.

\section{Fagara hyemalis (A.St.-Hil.) Engl.}

No se han encontrado diferencias en la anatomía foliar, ni en la de los domacios con la especie descripta anteriormente.

En la cavidad del domacio de $F$. hyemalis se encontraron ácaros adultos y deutoninfas de Tetranychus sp. (Tetranychidae).

\section{Balfourodendron riedelianum (Engl.) Engl. (Fig. 3)}

Se trata del conocido «guatambú» o «guatambú blanco», que crece en la Argentina solamente en las provincias de Misiones y Corrientes (Dimitri, 1974). Las hojas son compuestas, 3 (4)-folioladas.

Exomorfología del folíolo: obovado o elíptico; pubérulo a glabro; pelos simples unicelulares cortos y pelos pluricelulares glandulares caducos (Fig. 3, C, D y E); con puntos glandulares translúcidos; ápice foliar agudo o acuminado, brevemente involuto; base atenuada.

Domacios ubicados en las axilas de las venas de segundo y tercer orden, así como a lo largo de la vena de primer orden (Fig. 3, A); venación pinnada, camptódroma, broquidódroma; venas de segundo orden 10-20 pares, ángulo de divergencia 60-70 .

Anatomía de los folíolos: Epidermis uniseriada; la adaxial con células de tamaño algo mayor que la abaxial; estomas de tipo anomocítico, cuyas células oclusivas están dispuestas por encima de las otras células epidérmicas (Fig. 3, G y H); cutícula muy estriada, haciéndose la estriación más acentuada sobre las células oclusivas; índice estomático de 8,3 $\%$. Mesofilo con estructura dorsiventral; cavidades secretoras lisígenas distribuidas en toda la lámina y en el parénquima que rodea los haces vasculares. Vena media formada por haces vasculares abiertos rodeados de una vaina fina de esclerénquima; colénquima sobre la cara abaxial y adaxial.

Exomorfología del domacio (Fig. 3, A y B): Domacios en criptas, grandes o pequeños, con un poro de tamaño variable, elíptico o en forma de ranura en el ápice de un pequeño domo; 

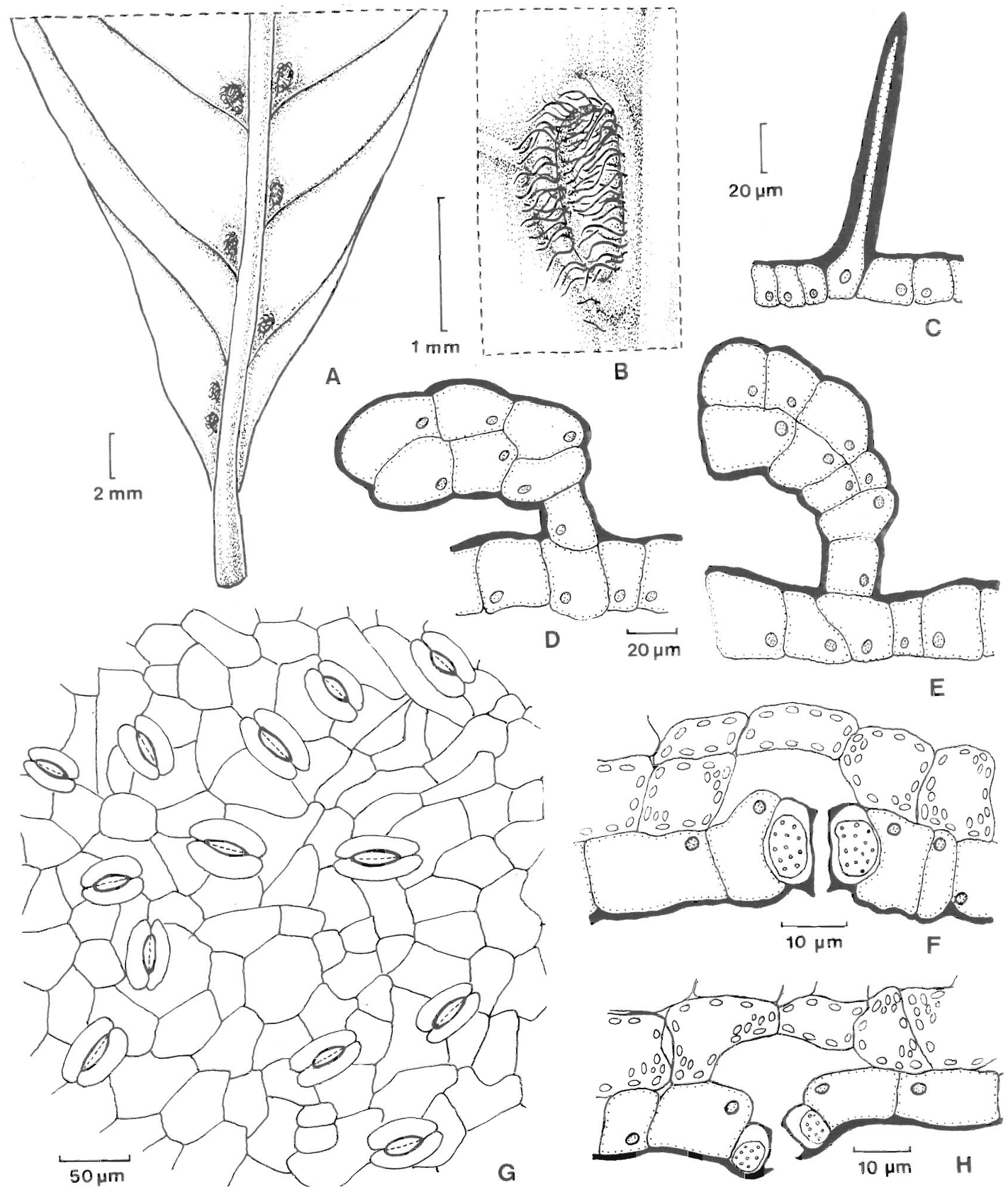

E

Fig. 3. Balfourodendron riedelianum (Tressens et al. 2757). A: cara abaxial de una porción de folíolo mostrando la posición de los domacios; B: detalle de un domacio; C: pelo simple unicelular; D y E: pelos glandulares de un folíolo joven; F: transcorte de un estoma de la epidermis del domacio; G: epidermis abaxiai del folíolo; H: corte transversal de un estoma de la cara abaxial del folíolo.

la cripta parcialmente hundida en el tejido foliar, cubierta de pelos simples mucho más largos que los del resto de la epidermis. Por su ubicación son primario-axilares (Stace, 1965).
En hojas adultas el número de domacios varía entre 20 y 30, su tamaño disminuye hacia el ápice de la lámina foliar. Estos domacios ya se observan en hojas muyy jóvenes, con folíolos 

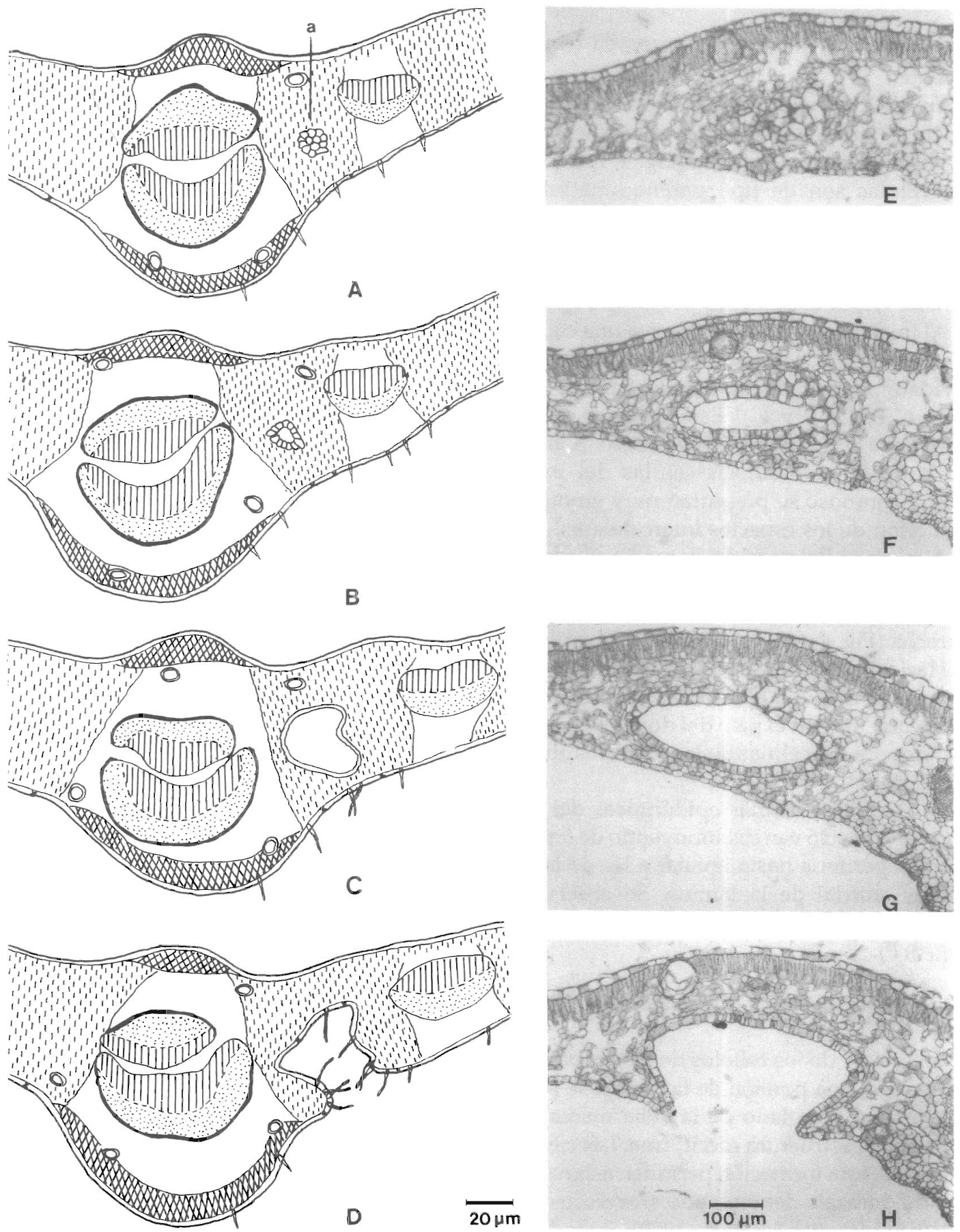

Fig. 4. Balfourodendron riedelianum (Tressens et al. 2757). A-D: representación esquemática de secciones transversales del domacio desde el extremo distal al proximal; E-H: fotomicrografías de zonas similares a las esquematizadas en A-D; a y e: grupo de células iniciales.

que no superan los $5 \mathrm{~mm}$ de longitud y su formación es anterior a la completa diferenciación de los tejidos del mesofilo.
Anatomía del domacio: Se realizaron transcortes seriados abarcando el domacio desde el extremo distal al proximal, como se muestra 
en la Fig. 4, la secuencia observada es la siguiente:

En el extremo distal del domacio se diferencia un grupo de células incoloras incluidas en el parénquima lagunoso (Fig. 4, A a y E e). Las células son de tipo parenquimático, de paredes ligeramente engrosadas, dispuestas desordenadamente. Se distinguen claramente de las células del clorénquima por su mayor tamaño y por la ausencia de cloroplastos.

Al iniciarse la cripta se observa una capa de células grandes, compactas, que delimitan una cavidad pequeña, transversalmente oblonga (Fig. 4, B, C, F y G). Esta capa de células constituye la epidermis del domacio. A ambos lados de la cavidad, las células del parénquima lagunoso se presentan muy juntas por reducción de los espacios intercelulares.

A la altura del poro del domacio se esbozan dos proyecciones convexas, que corresponden al reborde que delimita la abertura todavía estrecha (Fig. 4, D y H).

Hacia la parte media de la cripta, donde alcanza su máxima latitud, las células epidérmicas que forman el piso del domacio son más grandes que las células de la epidermis abaxial de la lámina.

Las restantes células epidérmicas del interior del domacio van disminuyendo de tamaño hacia la periferia hasta igualar a las de la epidermis abaxial de la lámina. Se observaron estomas y tricomas en el piso del domacio (Fig. 3, F).

\section{Discusión y Conclusiones}

En la base de los folíolos de Fagara pterota y F. hyemalis, una porción de la lámina se pliega y enrolla, a cada lado de la vena media, formando una estructura sacciforme. Las características de esta formación permiten asignarla al tipo de domacio denominado «revoluto» (Stace, 1965; Metcalfe \& Chalk, 1979). Stace (1965) describe este tipo de domacio como una porción especializada de la lámina que se pliega hacia abajo y hacia atrás como la solapa de un sobre.

Los estomas presentes en la cara abaxial de los folíolos de las dos especies de Fagara, faltan en la epidermis que tapiza los domacios. Esta ausencia se corresponde con las característi- cas del mesofilo en esta región, donde el parénquima lagunoso se va reduciendo hasta desaparecer en el margen foliar. Las dos especies presentan pelos simples unicelulares cortos.

Los ácaros hallados en el interior de los domacios, evidentemente usan estas estructuras como refugio.

Algunos autores (Jacobs, 1966; Brouwer \& Clifford, 1990; Gregory, 1990) restringen el término domacio a las estructuras localizadas en las axilas de las venas y no reconocen como domacios a los formados por el margen foliar revoluto. Como bien lo expresan Metcalfe \& Chalk (1979), la definición de Lundstroem es lo suficientemente amplia como para incluir cavidades de forma variada que se encuentran en casi cualquier parte vegetativa de la planta. El término domacio parece entonces apropiado para denominar a estas formaciones con estructura diferente al resto de la lámina y que determinan cavidades utilizadas por ácaros como alojamiento.

Se confirma la presencia de domacios tipo «cripta» o «lebetiforme» en Balfourodendron riedelianum. Estos domacios, que aparecen muy tempranamente en la ontogenia de la hoja, presentan la epidermis interna con estomas y abundantes pelos glandulares y no glandulares.

La presencia de los domacios es constante en las tres especies estudiadas.

\section{Agradecimientos}

Agradezco a la Lic. Sara Tressens quien dirigió este trabajo, pues sin su valiosa ayuda no hubiera sido posible la realización del mismo. A la Dra. Elena Ancibor, la lectura crítica del manuscrito. Al personal de la cátedra de Zoología Agrícola de la Facultad de Ciencias Agrarias-UNNE, la identificación de los ácaros. Al Sr. V. Maruñak, el montado de las láminas.

\section{Bibliografía}

ADAMOLI DE BARROS, M. 1960. Origem e formaçâo das domácias em Coffea L. Anais Esc. Super. Agric. «Luiz de Queiroz»17: 131-138

_ 1961a. Ocorréncia das domácias nas Angiospermas. Anais Esc. Super. Agric. «Luiz de Queiroz» 18: $113-$ 130. 
- 1961b. Domácias nas Angiospermas. Variaçoes na forma e na localizaçâo. Anais Esc. Super. Agric. «Luiz de Queiroz» 18: 132-146.

BROUWER, Y. M. \& H. T. CLIFFORD. 1990. An annotated list of domatia bearing species. Notes Jod rell Lab. 12:133.

DIMITRI, M. J. 1974. La flora arbórea del Parque Nacional Iguazú. Anales Parques Nac. 12: 1-180.

DIZEO DE STRITTMATTER, C. 1973. Nueva técnica de diafanización. Bol. Soc. Argent. Bot. 15 (1): 126-129.

DOTTORI, N. M. 1976. Morfología foliar en Celtis tala y C. pallida con especial referencia a los domacios. Kurtziana 9: 63-80.

ESCALANTE, M. G. 1961. El género Fagara en la Argentina. Bol. Soc. Argent. Bot. 9: 291-317.

GREGORY, M. 1990. Additional records of occurrence of domatia. Notes Jodrell Lab. 12: 34-50.

HICKEY, L. J. 1974. Clasificación de la arquitectura de las hojas de Dicotiledóneas. Bol. Soc. Argent. Bot. 16 (1-2): $1-26$.

JACOBS, M. 1966. Domatia. Fl. Males. Bull. 20: 1272-1273.

JOHANSEN, D. A. 1940. Plant microtechnique. McGrawHill Book Co. Inc. New York and London. 511 pp.

METCALFE, C. R. \& L. CHALK. 1950. Anatomy of the Dicotyledons 1. Clarendon Press, Oxford. 724 pp. 1979. Anatomy of the Dicotyledons 1. Clarendon Press, Oxford. 276 pp.

PEMBERTON, R. N. \& CH. E. TURNER. 1989. Occurrence of predatory and fungivorous mites in leaf domatia. Amer. J. Bot. 76(1): 105-112.

SPICHIGER, R \& L. STUTZ de ORTEGA. 1987. Rutaceae en Spichiger, Flora del Paraguay: 1-50.

STACE, C. A. 1965. Cuticular studies as an aid to plant taxonomy. Bull. Brit. Mus. (Nat. Hist.). Bot. 4(1): 1-78.

TRESSENS, S. G. 1981. Novedades para la flora de la provincia de Corrientes. Bonplandia 5 (15): 123-142. 